\title{
Kultuuritundlikkusest ja rändetausta tähendusest palliatiivravis ja hospiitsitöös patsiendinarratiivide näitel
}

\author{
Piret Paal \\ Paracelsuse meditsiinieraülikooli (PMU) õenduse uurimise ja \\ rakendamise instituudi uurija ja Maailma Tervishoiuorganisatsiooni \\ koostöökeskuse koordinaator \\ piret.paal@pmu.ac.at
}

\begin{abstract}
Teesid: Artiklis käsitletakse palliatiivravi- ja hospiitsitöö teemat patsiendinarratiivide näitel. Vaatluse all on 2016. aastal Münchenis, Saksamaal palliatiivpatsientidega läbi viidud süvaintervjuud. Intervjueerituist (37) pooled olid rändetaustaga. Teemaanalüüs näitas, et palliatiivravi ja hospiitsitöö oli paljudele patsientidele tundmata. Elu lõpuga seostati enamasti autonoomia kaotust ja lootust surmaabile. Erinevalt elu- ja haiguselugudest ja surma teemast oli elu lõpust rääkimine patsientidele suur väljakutse. Kahe patsiendigrupi võrdlus osutas, et rändetaustaga patsientidele oli iseloomulik nn kahe kodu sündroom. Viimane võib põhjustada kannatusi ja vajada professionaalide tähelepanu, eriti kui arvestada, et üks palliatiivravi ja hospiitsikultuuri eesmärk on anda patsientidele võimalus kodus surra. Autor väidab, et pole mingit põhjust rändetaustaga inimesi elu lõpus erinevalt kohelda, kuid küsimused: kas, millal ja milleks kultuuritundlikkus hospiitsitöös ja palliatiivravis vajalik on, vajavad endiselt analüüsimist.
\end{abstract}

Märksõnad: hospiitsikultuur, kultuuritundlikkus, palliatiivravi, ränne

2018. aasta novembris toimunud Astana kohtumine nimetab esmakordselt, et palliatiivravi peab olema kõigile kättesaadav ning et jätkusuutlik tervishoiusüsteem peab koosnema ennetus-, ravi-, rehabilitatsiooni- ja palliatiivteenustest (WHO 2018). Varasemalt on Maailma Tervishoiuorganisatsioon defineerinud neli suurt komistuskivi, mis globaalselt tõkestavad palliatiivteenuste arengut: 1. inimesed ei tea, mil moel palliatiivravi kasulik võib olla; 2 . kultuurilised ja sotsiaalsed tõkked, nagu uskumused, mis on seotud surma ja suremisega; 3. tervishoiutöötajate vähesed oskused ja teadmised; ning 4. kohalikud seadusandlused, mis piiravad tugevate valuvaigistite kasutamist (WHO 2015). Inimeste teadmatus ja niinimetatud kultuurilised ja sotsiaalsed tõkked on loonud olukorra, kus küsimus kultuuritundlikust palliatiivravist ja hospiitsitööst on 
pidevalt päevakorral (Cain et al. 2018; Evans et al. 2012; Florea 2012; Gunaratnam 2014; Gysels et al. 2012; Henke et al. 2017; Jansky et al. 2017a; Koffman 2014; Milberg et al. 2016; Paal \& Bükki 2017; Sarría-Santamera et al. 2016; Schrank et al. 2017), aga teadustöödel põhinevad andmed on kesised (Cain et al. 2018). Seepärast on järgnevad küsimused endiselt arutlemist väärt. Nimelt, kuidas analüüsida kultuuri mõju mitmekesises ühiskonnas loomata stereotüüpe ja stigmasid? Kuidas edendada kultuurisidusate vajaduste märkamist tervishoiu valdkonnas? Millised on kultuurisidusad komistuskivid palliatiivravis ja hospiitsitöös, millele WHO oma programmis vihjab?

Käesolevas artiklis käsitletakse kultuuritundliku palliatiivravi- ja hospiitsitöö teemat kirjanduse ja patsiendinarratiivi näitel. Esitatud mõtted põhinevad autori erinevatel kirjatöödel (Paal 2012; Paal et al. 2018; Paal 2018) ja 2016. aastal patsientidega läbi viidud süvaintervjuudel (37 intervjuud), millest on artiklisse nopitud hermeneutilis-teoreetilisi arutlusi ilmestavad tekstinäited. Intervjuudel põhineva teadustöö eesmärgid, meetodid ja tulemused on varem avaldatud inglise keeles (Paal \& Bükki 2017).

\section{Kultuuritundlikkus, kultuuripiiride hajumine ja hüperkultuur}

Kultuur kannab endas elutegevuseks vajalikke väärtusi ja suunab tegevusi, mida inimesed ühiskonna arengut silmas pidades tähtsaks peavad (Helman 2000). Kultuur võib tähendada nii kauneid kunste (muusika, maalikunst), ühiskonna arengut (demokraatia) kui ka inimese sisemist arengut uue ja parema mina suunas (moraal, viisakus, tähelepanelikkus, teadmised) (Tylor 2005 (1871): 358). Kultuuridefinitsioonid, mis üritavad määratleda kultuuri kui kollektiivide poolt ühiselt heakskiidetud väärtuste ja käitumisviiside kogumit, on üldistavad ja lähtuvad homogeense grupi või ühiskonna mallist (Trompenaars \& Hampden-Turner 2006: 52). Tänapäeva ühiskonnad on mitmekesised, neid rikastavad erinevate kultuuritaustadega inimesed, sellepärast eelistatakse ühe kultuuridefinitsiooni asemel erinevaid kontekstist sõltuvaid definitsioone. Kultuuri soovitatakse näha ja mõtestada kui üht võimalikku mõjutegurit, mis sõltub määratletud kontekstist ja küsimuseasetusest (Sarría-Santamera et al. 2016). Teadlaste ülesanne on püstitada stereotüüpidest vabu küsimusi (Henke et al. 2017; Paal 2018), et saada vastuseid, mis aitavad muuta tervishoiusüsteeme keeleliselt, kultuuriliselt ja meditsiiniliselt ühiskonnas valitsevatele mitmekesisustele avatumaks.

Kui kõneldakse mitmekesisusest (diversity), kultuurist ja kultuuritundlikkusest, siis kasutatakse sageli läbisegi mõisteid interkultuurne, multikultuur- 
ne, transkultuurne ja hüperkultuurne. Tihti on need mõisted tähendustega üleküllastatud ja seeläbi tähenduseta. Ka järgnevad inter-, multi-, trans-, ja hüperkultuuri definitsioonid on kokkuleppelised, kuid üritavad lüüa pilti kultuuritundlikkusest eelkõige saksa kultuuriruumis, kus sageli viidatakse ingliskeelsetele terminitele, kuid need on kohalikust kontekstist lähtuvalt saanud erineva tähenduse.

Interkultuurne (inter-cultural) tähendab seda, kui erineva kultuuritaustaga inimeste või gruppide kokkupuutest sünnib mingi kolmas kultuuriruum, mis eelnevat kahte kultuuri kas ühendab või teineteisest eemale lükkab (Foitzik \& Pohl 2011: 62). Anna Tsing (Tsing 2004) on sellist kultuuride vastastikust mõjutamist kirjeldanud kui friktsiooni (friction), mis kannab endas nii positiivseid kui ka negatiivseid lõimumisi. Cecil Helman kirjeldab aga, kuidas ränne ja erinevad migrantidevood on loonud olukorra, kus sotsiaalsed grupid ei ela üksteise kõrval, vaid läbisegi (Helman 2006) ning selle tulemusel toimuvad lõimumised mitte gruppide, vaid indiviidide tasandil. Sellised lõimumised on sageli kontekstisidusad: mõnes kontekstis integreerutakse, teises ollakse kas tahtlikult või tahtmatult autonoomsed (Paal 2018).

Multikultuurne osutab mitmekesisusele, kultuuriruumile, kus erineva taustaga inimesed ja grupid koos eksisteerivad ja tegutsevad. Selline kooseksisteerimine põhineb vastastikusel mõistmisel, tolerantsil ja ühiskondlikul kokkuleppel, milles liigutakse ühiste väärtuste suunas isiklikke ja grupikuuluvust defineerivaid väärtusi diskrimineerimata (Rommelspacher 2005: 175). Selline reguleerimata kooseksisteerimine valitses Saksamaal kuni 2005. aasta rahvaloenduseni, mil tervishoius toimus sotsioloogiline ja poliitiline pööre ning hakati rohkem tähelepanu pöörama rändetaustaga inimeste vajadustele (Razum 2010). Järgnenud diskussioon viis selleni, et 2010. aastal kuulutas kantsler Angela Merkel mõiste multi-kulti (saksa lühend sõnast multikulturaalne) tähendusetühiseks (Spiegel Online 2010).

Transkultuurseks peetakse ühiskonna muutumist ja liikumist ühest ühiskonnavormist teise. Kultuurid on sisemiselt pluralistlikud ja neis leidub kultuuripiire ületavaid jooni. Viimased saavad uue kuju ja klassikaline kultuur muutub. Need muutused määravad ka arusaamade ja normide kujunemist (Welsch 1995: 194-213). Tervishoiu- ja sotsiaaltööalases erialakirjanduses kasutatakse nimetatud mõistet sageli integratsioonitöö kirjeldamiseks. Selle ajendiks on soov muuta teised selliseks nagu "meie", aga mis on "meie" (kollektiivne identiteet), on saksa kultuuriruumis äärmiselt hägusalt defineeritud (Süddeutsche Zeitung 2018). Sellist lähenemist võib nimetada seisukoha epistemioloogiaks (standpoint epistemology). See viitab mitmekesisuse puudumisele või etniliste, rassiliste, sooliste või usuliste gruppide marginaliseerimisele (Fricker 2009; Milberg et al. 2016; Paal 2018), sellise töö keskmes on kujutlus 
mingist staatilisest identiteedist või homogeensest grupist. Just sellise lähenemise eest hoiatab Helman (2006), kutsudes meditsiiniantropolooge kriitiliselt kaasa mõtlema ja tegutsema.

Urbaanse elukeskkonna, kus räägitakse läbisegi kõiki maailma murdeid ja keeli, kirjeldamiseks kasutatakse ka mõistet hüperkultuur. Hüperkultuur kirjeldab vastandamise mõjul tekkinud piiride hajumist erinevate kultuurivormide vahel ning nende lähenemist ja lõimumist. See mõiste on seotud nii ruumi, aja kui ka üksikisiku identiteediga (Han 2005: 55). Paljudes Saksamaa suurlinnades on ligi $40 \%$ elanikest rändetaustaga, mis tähendab, et neis linnades valitseb lausa hüpermitmekesisus ning sellepärast peab mitmekesisus nii tervishoius, sotsiaaltöös kui ka teadustöödes olema iga probleemipüstituse lähtekohaks (Crawley 2005; Gunaratnam 1997; Sarría-Santamera et al. 2016).

Eelpool loetletud mõisted viitavad mitmekesisusest mõjutatud ühiskonna korraldamisele (diversity management), kus erinevate kultuuritaustadega inimesed üksteise kõrval elavad ja tegutsevad. Saksamaal tähendab see migrantide (vt allpool) vajaduste monitoorimist (Henke et al. 2017; Henke et al. 2015; Jansky \& Nauck 2015; Jansky et al. 2017a; Jansky et al. 2017b; PALQUALSUM 2016; Razum 2010; Salis-Gross et al. 2014; Soom-Amman \& Salis-Gross 2014; Wasner \& Kurz 2016) ja teenuste pakkumist mingile kunstlikult konstrueeritud indiviidi tüübile või gruppidele (EMZ 2018; PALQUALSUM 2016). Praegu valitsev seisukoha epistemioloogia tuleneb sellest, et nii poliitikud kui ka tervishoiuasutuste juhatused, otsuste langetajad, aga ka teadlased on kultuuritaustalt lähedased. Mitmekesisuse aktsepteerimine peab muutuma teadlikumaks ühiskonna ja ka tervishoiuasutuste tasandil. Otsuste (nagu ka teaduse) tegemisse tuleb kaasata võimalikult erinevaid inimesi, mis osutab osaluspõhiste uurimismeetodite rakendamise vajadusele ühiskonnas ja tervishoius (von Unger 2014). Ennustatakse, et homogeensed institutsioonid sunnitakse muutuma just seespidise surve mõjul. Kahjuks ei ole saksa ühiskond bi- või multikultuurse taustaga inimesi kui ühiskondlikku ressurssi avalikult tunnustanud. Projektipõhised erinevatele sihtrühmadele suunatud initsiatiivid koolitavad välja sillaehitajad (EMZ 2018), kes aitavad kaasa vastastikusele mõistmisele ja lõimumisele mitte ainult konkreetseid sõnu tõlkides, vaid ka olukordi laiemalt lahti mõtestades. Viimane omakorda muudab juba olemasolevad sotsiaal- ja tervishoiuteenused, s.h palliatiivravi ja hospiitsitöö, klientidele arusaadavamaks ja vastuvõetavamaks. Nende projektide peamiseks puuduseks on jätkusuutmatus, sest puuduvad rahastusskeemid, kuna tegemist pole riiklikult tunnustatud ravi- ja sotsiaalteenuste programmidega. 


\section{Ränne kui väljakutse tervishoiu- ja sotsiaaltööle}

Ränne tähendab tööealise elanikkonna juurdevoolu, rahvastiku juurdekasvu, aga ka kohustust kaasata rändetaustaga inimesi ühiskonda ja pakkuda neile muu elanikkonnaga sarnaselt teenuseid. Rändetaustad on väga erinevad, selle hulka kuuluvad siseränne, immigratsioon ja emigratsioon (WHO 2016). Paljud inimesed on sunnitud oma kodudest lahkuma mõne looduskatastroofi või sõja tõttu, teised lähevad vabatahtlikult kas seiklema, õppima või tööle. Isegi kui tegemist on suurte inimmassidega, kes ühekorraga saabuvad teatud regioonist, on iga indiviidi rändepõhjused ja -lugu erinevad. Ka siis kui ränne toimub ühe maa piirides, külast linna, põhjast lõunasse, võivad sellel olla tagajärjed, mis võivad tekitada koduigatsuse (Gunaratnam 2014; Paal 2018). Ränne on alati ja igal pool oluline eluetapp, murrang, mis toob kaasa nii positiivseid kui ka negatiivseid muudatusi elukorralduses aga ka maailmavaates.

Statistika ja erinevad ametid üritavad jätkuvalt määratleda rändetaustaga inimesi nende päritolumaa, etnilise kuuluvuse, rahvuse, sünnikoha ja muude tunnuste alusel, kuid alati leidub inimesi, kes ei sobi ühtegi neist gruppidest, kelle eksistentsist pole riik teadlik või kelle jaoks rahvusel või etnosel pole mingit tähtsust (Razum et al. 2016). 2015. aasta sügisel olid Saksa Statistikaameti definitsiooni kohaselt rändetaustaga inimesed (Menschen mit Migrationshintergrund) need, kes olid Saksamaale tulnud hiljem kui 1949. aastal või nende järeltulijad. Kaks aastat hiljem definitsiooni kohendati ja praegu on migratsioonitaustaga inimesed kõik, kes on tulnud Saksamaale pärast 1955. aastat, aga ka Saksamaal sündinud välismaalased ja Saksamaal saks-lastena sündinud isikud, kelle üks vanematest on kas rändetaustaga või Saksamaal sündinud välismaalane:

nach 1955 auf das heutige Gebiet der Bundesrepublik Deutschland Zugewanderte, sowie alle in Deutschland geborenen Ausländer und alle in Deutschland als Deutsche Geborenen mit zumindest einem nach 1955 zugewanderten oder als Ausländer in Deutschland geborenen Elternteil. (Statistisches Bundesamt 2017)

Selle definitsiooni suureks puuduseks on asjaolu, et migrantideks liigitatakse inimesed, kellel isiklik rändekogemus puudub ning välja jäetakse need, kes on rändetausta ja kogemusega, aga saabunud Saksamaale sõjapõgenikena näiteks Teise maailmasõja ajal.

Autori poolt 2016. aastal läbi viidud uurimus (Paal \& Bükki 2017) näitas, et rändetausta määratlemine tervishoiu ja sotsiaaltöö kontekstis on väga keeruline. Silmaga vaadates ja kõrvaga kuulates polnud rändetaust sageli üldse märgatav. Alles patsientide elulugusid kuulates selgus, et mõned neist on sündinud 
välismaal, aga elavad juba aastaid Saksamaal, räägivad ainult saksa keelt või lisaks emakeelele aktsendivaba saksa keelt. Teised on vahetanud kodakondsust vaid sellepärast, et riigikord ja riigipiirid on muutunud, aga side konkreetse riigikorra ja rahvusliku mentaliteediga puudub täiesti. Kolmandad kuuluvad pagulaste, hiliste väljarändajate või taasasustajate hulka, omades saksa või mingeid muid etnilisi juuri. Sellest tuleb järeldada, et kui eriline välimus, aktsent või eksootiline nimi puudub, jääb rändetaust sageli märkamatuks. Vastupidiselt aga võivad need samad aspektid ahvatleda inimesi migrantideks tembeldama, eriti, kui tegemist on kohalike etniliste vähemuste esindajatega.

\section{Palliatiivravi ja hospiitsiteenus migrantidele?}

Nagu eelpool mainitud: pikka aega ei suunatud ega korraldatud Saksamaal kultuurilist mitmekesisust ühiskondlikult. Elati usus, et generatsioon "Gastarbeiter" töötab Saksamaal ja pöördub pensionile jäädes tagasi oma kodumaale (Razum 2010). See lõi seadusandluse tasandil väga liberaalse olukorra, milles kõigil oli võimalik säilitada oma kultuurile iseloomulikke jooni, rääkida oma keeles ning samas vastavalt vajadusele ja võimalustele saksa ühiskonda integreeruda. Selline poliitiline koordineerimatus tähendas ka seda, et paljud rändetaustaga inimesed ei saanud pikka aega ühiskonnakorralduses kaasa rääkida ning olid sunnitud elama niinimetatud paralleelühiskonnas, kus otsuseid tehti nn juhtkultuuri (Leitkultur) vajaduste ja parema äranägemise põhjal.

Alles 2005. aasta rahvaloendus tõstatas vananevate ja hooldust vajavate rändetaustaga inimeste küsimuse (BAMF 2005). Tekkis küsimus, et kui Gastarbeiter-generatsioon tagasi ei pöördu, kes nende eest hoolitseb ning kuidas ja kas neil on erivajadusi. Eelkõige võeti tähelepanu alla türgi päritolu migrandid (Razum 2010; Razum et al. 2016), unustades, et pärast Teist maailmasõda on inimesi tulnud Saksamaale Balkanimaadest, Venemaalt, Ida-Euroopast, Lähis-Idast ja paljudest teistest piirkondadest (Bade et al. 2011). Kuigi ligi 90\% rändetaustaga inimestest on tööealised (BAMF 2015), vajavad ka nemad (või nende lapsed ja vanemad) varem või hiljem hoolde-, ravi- ning ka palliatiivravi ja hospiitsiteenuseid.

Kuidas mõjutab rändetaust inimeste otsuseid elu lõpul? Selle küsimuse ümber on tekkinud palju erinevaid teooriaid, aga stereotüüpidest vabu empiirilisi uurimistöid on tehtud suhteliselt vähe. Kui olemasolevaid teooriaid omavahel võrrelda, tuleb ilmsiks, et kõigi teooriate keskmes on indiviid oma isiklike vajaduste ja väärtushinnangutega ning selmet teatud gruppe eristada, soovitatakse keskenduda sellele, mis kõiki ühendab (Bosma et al. 2010). Kas sellest tuleks järeldada, et kultuuritaust polegi oluline? Siiski, ka elu lõpul on inimene jätkuvalt erinevate kultuuride mõjuväljas. Etniline taust, keeleoskus ja -oskamatus, 
emantsipatsioon, religioosne kuulumine või kuulumatus, elukeskkond, ravi-ja hooldeteenuste kättesaadavus, perekonna ja lähedaste arusaamad elu lõpust ja surmast või konkreetse hospiitsi või palliatiivraviosakonna kultuur, mõjutavad indiviidi otsuseid kuni hüvastijäturituaalide ja matusteni.

Otsides kirjandusest vastust küsimusele raskelt haigete migrantide erivajadustest elu lõpul tuli järeldada, et mitmekesises ühiskonnas oleks vale analüüsida inimeste vajadusi teatud grupikuuluvuse põhjal, sest pealtnäha ka kõige homogeensemas grupis valitseb suur heterogeensus (Bosma et al. 2010; Crawley 2005; Florea 2012; Galanti 2000; Helman 2006). Kui uurimise objektiks on inimeste valikud ja vajadused elu lõpul, tuleb alustada ühiskonna poolt pakutava analüüsimisest, sest sellel (sõltumata kultuuritaustast) on otsene mõju meie tervisekäitumisele ja valikutele (Paal 2010).

\section{Palliatiivravi ja hospiitsitöö patsiendi perspektiivist}

Maailma Tervishoiuorganisatsioon rõhutab, et "palliatiivravi on oluline komponent integreeritud ravis nii noortele kui vanadele kogu elu jooksul" (WHO 2014). Palliatiivravi peamine eesmärk on võimaldada inimestele head elukvaliteeti vaatamata haigusega seotud probleemidele. Palliatiivravi keskmes on kompleksne patsiendi ja tema lähedaste vajadustest lähtuv koordinatsioonitöö ja ravi. Palliatiivravi eesmärk on leevendada sotsiaalseid, psühholoogilisi, ja spirituaalseid pingeid multiprofessionaalselt ja interdistsiplinaarselt, lähtudes patsiendi sotsiaalsest kontekstist ning tema perekonna võimalustest ja vajadustest. Perekond ja sõbrad moodustavad palliatiivravis keskse tugisüsteemi. Pole oluline, kas patsienti ravitakse haiglas, hospiitsis, hooldushaiglas, vanadekodus või ambulatoorselt, kõigil tervishoiutöötajatel peavad olema valmidus ja oskused, et märgata ning hinnata patsientide ja nende lähedaste psühhosotsiaalseid ja spirituaalseid vajadusi ning pakkuda neile professionaalset, aga ka personaalset tuge ja abi (Carduff et al. 2018; Munday et al. 2003; Pask et al. 2018).

Saksamaal algas teadlik palliatiiv-ja hospiitsikultuuri arendamine 25 aastat tagasi. Riigi ja paljude erainitsiatiivide toetusel on palliatiivravi ja hospiitsiteenused Saksamaal väga kiiresti arenenud. Piirkonnast sõltuvalt on tekkinud tihe võrgustik erinevatest teenusepakkujatest. Tervishoiuturule on lisaks statsionaarsetele institutsioonidele tulnud mitmed spetsialiseeritud palliatiivravi pakkujad, valu- ja hingamisambulantsid, mis pakuvad oma teenuseid patsientide kodudes. Erinevalt Suurbritanniast on Saksamaale omane, et palliatiivravi ja hospiitsiteenust üritatakse iga hinna eest lahus hoida. Sellise kahesuunalise arengu tagamaid ja nende teenuste ideoloogilisi nüansierinevusi on suhteliselt keeruline mõista ning see teema vajab kindlasti eraldi analüüsi. Lisaks on oluline märkida, et paljud hospiitsid elavad eraisikute annetustest, riiklik toetus katab vaid osa kuludest. 
Autori poolt läbi viidud uurimus osutas, et patsiendi seisukohast on selline kahestumine pigem negatiivne ja segadust külvav. Küsisin patsientidelt "Mis on palliatiivravi?" ja "Mis on hospiits?" Suur hulk patsientidest ei olnud palliatiivravist midagi kuulnud või seostasid seda terminaalfaasi ja surmaabiga, lisades: "Mina pole ju veel omadega nii kaugel?"

Ma arvasin, et palliatiivravi on seotud suremisega, see päris lõpp, see viimane lühike jupp. Aga ma sain teada, mis see tegelikult tähendab ja see on imeline. See tähendab kroonilise haiguse sümptomite vähendamist erinevate vahenditega. (016)

Elukvaliteedi parandamine, sümptomipõhine ravi ja ööpäevaringne hoolekanne, vabatahtlike töö ning lähedaste toetamine jäävad sellistes vestlustes tahaplaanile. Seepärast usuvad patsiendid kindlalt, et palliatiivravi võimaldab neil vajaduse tulles kannatused lõpetada.

Ma veel mõne aja pean vastu ja siis ma loodan, et saan kuskilt mingi ravimi, mille abil ma magama jään ning ülehomseks on kõik möödas. Ma loodan, et see institutsioon [hospiits] mind selles asjas ravimitega aitab. (003)

Hospiitsiga seostub surm, aga mõnikord, keelelisest taustast sõltuvalt, ka vaestemaja ja orbudekodu. Patsientide jaoks ei ole sõnal hospiits hoolitseva ja inimesest hooliva asutuse tähendust, vaid tegemist on kohaga, kus kannataja peab end koera kombel kerra tõmbama, et elul jalust ära saada.

Minu jaoks on hospiits alati see päris viimane mis üle jääb, ma ei saa sellest rääkidagi, mul on hea meel, kui ma nendega tegelema ei pea, see ei ole seotud nende inimestega. See on minu hirm. Ma pole ju veel nii vana! Ma oleksin veel hea meelega natukene elanud. (005)

Patsientide jaoks on palliatiivne ravi sageli paradoks. Kui kuratiivne ravi asendatakse palliatiivraviga tekitab see tunde, et patsiendi heaks enam midagi ei tehta. Isegi kui patsiendid mõistavad, et täielik tervenemine pole võimalik, ei suuda nad oma harjumuspärast tervisekäitumist muuta ning kasutavad vastavalt sisetundele ja lähedaste soovitustele lisaks palliatiivteenusele ka erialaarstide, haiglate ja kiirabi teenust. Kuna ka tervishoiutöötajate seas on palliatiivraviga seotud teenuste pakkumise osas suur teadmiste puudujääk (WHO 2014, WHO 2015), siis ei jää palliatiivravi- ja hospiitsiteenuse pakkujatel muud väljapääsu kui patsienti toetada just seal ja sel hetkel, kus ta parasjagu on.

Ühiskondlik teadlikkus palliatiiv-ja hospiitsiteenuse olemusest on endiselt puudulik. Palliatiivravist või hospiitsiteenusest saavad patsiendid teada enamasti täiesti juhuslikult, tänu tuttavatele-naabritele, või mõne ajaleheartikli 
kaudu. Kurb on see, kui sellele on eelnenud kuude pikkune valu käes vaevlemine, sest arstide sõnul ei ole patsiendi heaks enam võimalik midagi teha.

Mul olid kohutavad valud. Ma olen otsekui põrgus käinud ja mitte ainult üks päev. Seda pole võimalik endale ette kujutada. [---] Ja kui siis abi ei saa, sest sind pole enam võimalik aidata. Nad ei ütelnud, et me saadame teid valukliinikusse. Mitte midagi. See on kole, ma ei taha sellest mõtelda. (026)

See näitab, et palliatiivravi teenuse integreerimine Saksa meditsiini- ja tervishoiusüsteemi ei ole vaatamata 25 aasta pikkusele tööle täielikult korda läinud.

\section{Surmast rääkimine on lihtsam kui elu lõpule mõtlemine}

Inimesed elavad oma elu surmamõtet tõrjudes. Sellepärast leidub alati neid, kes keelduvad surmast rääkimast, uskudes, et see toob surma lähemale. Ettepanek vastaval teemal vestelda võib lõppeda patsiendi eemaletõmbumisega ja sellepärast ei tea teadlased ega ka tervishoiutöötajad selliste patsientide mõtetest palju. Teised valivad hoolikalt, kellega, kas üldse ja kuidas surmast rääkida. Kolmandatele on surmateemast rääkimine väga oluline. Sellesse vestlusesse põimitakse sageli ka küsimus elu lõpu (Lebensende) kohta.

See elu lõpp on selline mõiste. Mõteldakse, et... no tõesti, me ei tea ju ja sellepärast... sõnadel on selline tugev mõju. Seda peaks põhjalikult analü̈̈sima. Ma ei tea, mis palliatiiv tähendab, aga kui me sellest räägime, et nü̈̈d on lõpp, siis hakkavad ka need, keda see puudutab mõtlema, et kas nü̈̈d on asi nii kaugel? (032)

Patsientidega vesteldes selgus, et elu lõpul on patsientide jaoks üsna spetsiifiline tähendus, millega seonduvad valu, õhupuudus, kannatused, mobiilsuse ja enesekontrolli kaotus. Millal elu lõpp saabub ja mida endaga kaasa toob, oli patsientide jaoks nii painav teema, et sellest räägiti sageli ainult ridade vahel ja vihjetes. Mõnikord näis, et surmast ja suremisest oli rääkida lihtsam kui elu lõpust, sest surm, isegi kui surma ei oodata, päästab elu lõpu kannatuste käest.

Ma olen alati ütelnud, et kui asi nii kaugel on, siis on ta nii kaugel. See ei morjenda mind. Ma saan selle teadmisega elada. Maailm pöörleb ka ilma minuta edasi (naerab) (034)

Erinevalt surmast, mida kas kardetakse, oodatakse või mõtetes ja sõnades eemale peletatakse, on elu lõpu teema see, mis ilmselgelt vajab käsitlemist ja 
millest tuleb inimestega rääkida, et vähendada nende hirme ja kartusi. Elu lõpust rääkimine, eriti vastavate vestluste algatamine, on konkreetne väljakutse kõigile palliatiiv- ja hospiitsikultuuri arendajatele ja esindajatele, sest millal algab elu lõpp? Filosoofilises võtmes võiks väita, et elu lõpp algab inimese loomise hetkest. Mida tähendab palliatiivravi ja hospiitsiteenus elu lõpus? Praktika näitab, et elu lõpul on nii palliatiivravis kui hospiitsikultuuris hulgaliselt eri tähendusi kuni väiteni, et elu lõppu pole olemaski. Täpsem sõnastus ja sõnakasutus aitaks mõningaid olulisi teemasid käsitleda ilma surma- ja suremisega seotud kultuuri- ja keeletabudesse takerdumata, kuid see vajab hoolikat eeltööd.

\section{Koduigatsus kui hingepide ja -piin}

Kui eelnev kehtis kõigi küsitletud patsientide puhul, siis rändetaustaga patsiendid rõhutasid, et Saksamaa meditsiiniteenused ja tervishoiusüsteem on väga kõrgel tasemel ja patsientidel on tervishoiuteenustele väga hea juurdepääs. Paljud rändetaustaga patsiendid olid veendunud, et oma kodumaal oleksid nad juba ammu surnud, sest sealne tervishoiusüsteem on korrumpeerunud ja allapoole igasugust arvestust.

Kodus olles olin ma alati terve. Ma olen ainult kuulnud ja näinud, kuidas seal arstiabi antakse. Indoneesia ja Saksamaa on muidugi väga erinevad. Ja mul on väga hea meel, et ma siin haige olen. Ma nägin, kuidas mu vennanaine eelmise aasta märtsis suri. Ma olin kolm kuud seal ja see oli üks katastroof. Ei mingit haigekassat. Kõik tuleb ise maksta. Kõik maksab terve varanduse. Mu vend ei saanud enam tööl käia, sest pole hospiitsiteenust ega hooldeteenust, mitte midagi, kõik jääb pere hooleks. Muidugi meil pere hoiab rohkem kokku kui siin, aga palliatiivravi oleks siis vaja läinud. Selle pärast olen ma ise väga rahul ja tunnen ennast hästi. (007)

Mul on koolivend arst ja ta ütles, et kui ma oleksin Venemaale jäänud, oleksin ma ruineeritud ja omadega läbi, kuna arstiabi on kaputt. Ma olen tänulik, et ma Saksamaal olen. Minu haigusega 8-9 aastat, see on hea aeg. Arstiabi kinkis praktiliselt need aastad mulle. (036)

Isegi siis kui raviteenuste võrk on hästi arenenud, on juurdepääs nendele teenustele palju aeglasem ja erasektori poolt pakutavad tervishoiuteenused maksavad palju. See mõjutab patsientide otsuseid. Raskesti haiged inimesed ei pöördu tagasi oma kodumaale, vaid jäävad siia, kus nad on n-ö süsteemis sees ja end seetõttu kindlalt tunnevad. 
Tagasipöördumise üle oleme mõtteid mõlgutanud küll, aga meil pole USAs haigekassa kindlustust. Loomulikult, ei mõtle me ainult kindlustuse peale, aga see on tähtis. [---] Lihtsam on siia jääda, vähemalt praegu. Tjaa. (023)

Intervjuud osutasid, et rändetaust võib põhjustada kannatusi, mis vajavad ilmtingimata palliatiiv- ja hospiitsitöötajate tähelepanu. Palliatiiv- ja hospiitsitöös rõhutatakse sageli, kui tähtis on patsientidele ja lähedastele võimalus kodus surra. Rändetaustaga inimestel võib kodul olla mitu tähendust ja seepärast võib mõte kodus suremisest olla nende patsientide jaoks samuti mitmetähenduslik. Paljud rändetaustaga inimesed tunnevad, et on kodus Saksamaal, aga neil on veel mingi koht, mida nad nimetavad koduks. Mõte kodust ja koju tagasipöördumisest võib olla jõudu andvaks allikaks, aga põhjustada ka muret ja kannatusi.

See on üks igavene siia ja sinna, süda on rebenenud kodumaa ja kodu vahel, see teeb mind vahel väga kurvaks (oeh) eriti kui haige olla, siis ma mõtlen oma lapsepõlve peale, kui ilus on kodus olla. Aga siin jälle, siin on nii palju võimalusi, mida ära kasutada, siis on jälle raske. (007)

Sellist kahetist olukorda võiks nimetada kahe kodu sündroomiks (ZweierleiZuhause-Syndrom). Mida see endas kannab? Koju tagasipöördumine tähendaks tuttavatest tugistruktuuridest lahti ütlemist, mis eelkõige patsientide füüsilist seisukorda arvestades oleks paras julgustükk. Paljud neist on juba aastaid haiglate ja arstide vahel jooksmisest väsinud ega soovi enam muud kui rahu ja sümptomipõhist ravi. Lisaks on paljud teadlikud, et kodus vastavad teenused puuduvad või on kättesaadavad vaid erakliinikutes, ja see maksab palju. Teiseks, igapäevane sotsiaalvõrgustik nagu perekond, sõbrad-naabrid-tuttavad, kes tarvilikku tuge ja lohtu pakuvad, on eelkõige ikkagi Saksamaal. Teises kodus võib selline tugi olla aastakümnete möödudes väga hapraks jäänud või täiesti puududa. Lisaks võib hingevalu põhjustada tunne, et nõrgana ja viletsana ei ootagi keegi sind koju tagasi. Oodatakse ikkagi neid, kes ise suudavad endaga hakkama saada, teisi aidata ja abi pakkuda.

Ma tahan muidugi koju minna, aga ma pean ootama kuni olukord stabiliseerub, pean kontrollis käima nende metastaasidega ajus. [---] Silmakliinikus nad ehk leiavad midagi. Mina pean ootama, et paremaks läheb, sest kui ma nii lähen, poolpimedana, mida ma seal teen üldse? (027)

Niisiis on rändetaustaga patsiendid oma sõnade kohaselt lõksus.

Inimesed jäävad pensionile, tahavad kodus surra, eks ole? Aga kahjuks oleme me siin kõik köidikutega kinni, sest peaaegu kõigil on lapsed, lapselapsed ja nii edasi ja nii edasi... (009) 
Siiski põevad paljud küsitletutest koduigatsust, mõtlevad oma lapsepõlvele, perekonnale, ning mõte koju naasmisest ja kodus suremise võimatusest võib tekitada sotsiaalset kibestumist ja hingelisi kannatusi. Tegemist on kompleksse probleemipõimikuga, mis vajab kindlasti erinevate professionaalide ja ka koolitatud vabatahtlike tähelepanu, sest muidu võib ka kõige osavam sümptomipõhine ravi osutuda kasutuks.

\section{Diskussioon: mitmekesisuse printsiip hospiitsitöös ja palliatiivravis}

Kultuuritundlikkus viitab eelkõige inimeste valmidusele teadlikult vältida võõristamist, stereotüpiseerimist ning oskust näha inimest kui indiviidi tema nimest, nahavärvist, aktsendist, kultuuritaustast, sotsiaalsest staatusest, harjumustest, eluviisist, maailmanägemusest ja uskumustest sõltumata (Koffman 2014). Juba 2006. aastal kirjutas Cecil Helman, et just siin avaneb meditsiiniantropoloogidele rida uusi võimalusi, et erinevatel tasanditel võtta üle vahendaja, nõustaja, aga ka kriitilise sõbra roll (Helman 2006). Viimane on Helmani meelest oluline, et võidelda meditsiinis, sotsiaaltöös, ja õenduses kasutusel olevate lihtsustatud "retseptiraamatute" vastu, mis käsitlevad identiteeti staatilisena ja etnilisi gruppe homogeensetena ega pööra piisavalt tähelepanu sotsiaalsetele ja majanduslikele aspektidele, mis kaasnevad haigestumise ja haige olemisega.

Uurimistöid, mis adekvaatselt osutaksid, et rändetaust seondub konkreetsete erivajadustega, on vähe ja nende puhul tuleb alati küsida, kas tegemist pole mingite kunstlikult tekitatud staatiliste identiteetide ja homogeensete etniliste rühmadega, mille eest hoiatas Helman (Helman 2006). On teada, et erivajadused võivad esile tulla rändetaustaga eakate inimeste seas, kes ei suuda muganduda, ja puudutada migratsioonitaustaga lapsi (Pollack \& Kronebusch 2009). Rändetaust muutub probleemiks alles siis, kui see põimub teiste peamiselt sotsiaalset laadi toimetulekuprobleemidega, nagu vaesus, töökaotus või sassiläinud peresuhted. Sellises olukorras pole rändetaust primaarne, vaid sekundaarne probleem, mille konkreetset tähendust saab mõista vaid kitsamas kontekstis, lähtudes konkreetse inimese ja tema perekonna vajadustest.

Kuna küsimused: "Kas te olete migrant?" või "Kust te pärit olete?" võivad ühiskonna mitmekesisust silmas pidades omandada negatiivse tähendusvarjundi, võiksid professionaalid kasutada pisut erinevat screening-küsimust, mida võib kartuseta esitada kõigile patsientidele:

Te elate praegu siin [...]. Kas on veel mõni teine koht, kus te end kodus tunnete? 
Selles küsimuses puudub vihje mingile teatud rühmakuuluvusele, mis võiks tunduda diskrimineeriva või stereotüpiseerivana. Patsiendi vastuse põhjal on võimalik välja selgitada rändekogemuse olemasolu. Edasi on võimalik esitada küsimusi, mis seotud kodu, kodutunde ja võimaliku koduigatsusega. Siinkohal on oluline meeles pidada, et koduigatsus võib olla nii valus teema, et inimesed on aastakümneid harjutanud end sellest mitte rääkima ja mõtlema. Seepärast on vastuseid kuulates vaja jälgida ka mitteverbaalseid signaale, nagu näiteks veekalkvel silmad või suitsupaki järele haaramine.

Saksa kontekstis on ühiskondlik arusaam rändest ja selle tähendusest õhuke ja ebatäpne. Inimeste liigitamine migrantideks ja kohalikeks on pigem seotud traditsiooni, poliitika, ametkondade ja bürokraatiaga. Ohtlikuks muutub selline lähenemine, kui see mõjutab tervishoiu-, sotsiaal- ja meditsiinitöötajate otsuseid (Buiting et al. 2008; Galanti 2000). Seepärast tuleb kultuuritundlikkust arendada mitmel tasandil simultaanselt, sest mitmekesises ühiskonnas elavate inimeste vajaduste rahuldamine eeldab diferentseeritud lähenemist (Jovanovic 2012; Kai et al. 2011; Koffman 2014; Kumagai \& Lypson 2009; Milberg et al. 2016). Tervishoiusüsteem, mis suudaks integreerida kõikide erivajadustega inimeste ja gruppide eelistusi, on utoopia, seepärast on vaja keskenduda konkreetsete kitsaskohtade (nagu näiteks keelebarjäärid) kõrvaldamisele olemasolevas süsteemis (Gießler 2011). Spetsiaalselt teatud etnilise taustaga inimestele pakutavate teenuste arendamine võib olla otstarbekas piirkondades, kus üks rahvusrühm või etniline grupp selgelt domineerib, mis tähendab, et on olemas nii teenuse tarbijad kui ka pakkujad. Siiski võib mitmekesises elukeskkonnas "migrantidele" kui erivajadustega inimestele suunatud teenuste pakkumine tekitada mõistmatust ja isegi hirmu. Mõte eriosakonnast, kus elavad ainult moslemid või vene keelt rääkivad inimesed, tundub kahtlase, isegi ohtlikuna, eriti siis kui konkreetse inimese maailmapildi keskmes on olnud mitmekesisus kui elu rikastav aspekt.

\section{Kokkuvõte}

Palliatiivravi ja hospiitsitöö keskmes on inimene ja tema lähedased konkreetsete eelistuste ja vajadustega. Kuigi inimestel on kombeks oma elu hõlbustamiseks kõike liigitada ja sedelitega märgistada, hoiatab mitmekesisuse printsiip sellise lähenemise eest tervishoiu valdkonnas. Olemasolev kirjandus kultuuritundlikust palliatiivravist ja hospiitsitööst ei anna mingit põhjust väita, et migrantidele suunatud teenus peaks olema erinev üldisest teenusest. Pigem vastupidi: peamine väljakutse on selles, kuidas tagada kõigile abivajajatele kultuuri- ja sotsiaalsete tõkete vaba juurdepääs vastavale teenusele. Selmet 
tuvastada ja rõhutada erinevusi, soovitab mitmekesisuse printsiip keskenduda ühisosale ja otsida sarnasusi. See tähendab ka edaspidi rutiinsete mõtlemisviiside, müütide ning traditsioonide murdmist nii isiklikul, institutsioonide kui ka ühiskonna tasandil.

\section{Kirjandus}

Bade, Klaus J. \& Emmer, Pieter C. \& Lucassen, Leo \& Oltmer, Jochen (toim) 2011. The Encyclopedia of European Migration and Minorities. From the 17th century to the present. Cambridge University Press.

BAMF 2005 = Leben in Deutschland. Haushalte, Familien und Gesundheit - Ergebnisse des Mikrozensus (https://www.destatis.de/DE/Publikationen/Thematisch/Bevoelkerung/ HaushalteMikrozensus/HaushalteFamilienGesundheitPresse5122119059004.pdf? blob=publicationFile -22 . november 2018).

BAMF 2015 = Das Bundesamt inZahlen 2015? Bundesamt für Migration und Flüchtlinge (kodulehekülg http://www.bamf.de/DE/Startseite/startseite-node.html - 15. november 2018).

Bosma, Harvey \& Apland, Lars \& Kazanjian, Arminée 2010. Cultural conceptualizations of hospice palliative care: more similarities than differences. Palliative Medicine 24 (5), lk 510-522 (doi: 10.1177/0269216309351380).

Buiting, Hilde \& Rietjens, Judith \& Onwuteaka-Philipsen, Bregje \& van der Maas, Paul \& van Delden, Johannes \& van der Heide, Agnes 2008. A comparison of physicians' endof-life decision making for non-western migrants and Dutch natives in the Netherlands. European Journal of Public Health 18 (6), lk 681-687 (doi: 10.1093/eurpub/ckn084).

Cain, Cindy \& Surbone, Antonella \& Elk, Ronit \& Kagawa-Singer, Marjorie 2018. Culture and Palliative Care: Preferences, Communication, Meaning, and Mutual Decision-Making. Journal of Pain and Symptom Management (doi:10.1016/j.jpainsymman.2018.01.007).

Carduff, Emma \& Johnston, Sarah \& Winstanley, Catherine \& Morrish, Jamie \& Murray, Scott A. \& Spiller, Juliet \& Finucane, Anne 2018. What does 'complex' mean in palliative care? Triangulating qualitative findings from 3 settings. BMC Palliative Care 17 (1) (doi: 10.1186/s12904-017-0259-z).

Crawley, Lavera M. 2005. Racial, cultural, and ethnic factors influencing end-of-life care. Journal of Palliative Medicine 8 (Suppl 1), lk 58-96 (doi: 10.1089/jpm.2005.8.s-58).

EMZ 2018 = MiMi Bayern. Mit Migranten für Migranten - Interkulturelle Gesundheit in Bayern. Ethno-Medizinische Zentrum e. V. (http://www.ethno-medizinisches-zentrum. de/index.php?option=com_content\&view=article\&id=28\&Itemid=4 -15 . november 2018).

Evans, Natalie \& Meñaca, Arantza \& Andrew, Erin V. W. \& Koffman, Jonathan \& Harding, Richard \& Higginson, Irene J. \& Pool, Robert Gysels, Marjolein 2012. Systematic Review of the Primary Research on Minority Ethnic Groups and End-of-Life Care From the United Kingdom. Journal of Pain and Symptom Management 43 (2), lk 261-286 (doi: 10.1016/j.jpainsymman.2011.04.012).

Florea, Mira 2012. Cross-Cultural Issues in Academic Palliative Medicine. Chang, Ester \& Johnson, Amanda (toim). Contemporary and Innovative Practice in Palliative Care. Intechweb.org, lk 3-16 (doi: 10.5772/32477). 
Foitzik, Andreas \& Pohl, Axel 2011. Das Lob der Haare in der Suppe. Selbstreflexivität Interkultureller Öffnung. Scharathow, Wiebke \& Leiprecht, Rudolf (toim). Rassismuskritik. Band 2: Rassismuskritische Bildungsarbeit. Schwalbach: Wochenschau-Verlag, lk 61-76.

Fricker, Miranda 2009. Epistemic Injustice: Power and the Ethics of Knowing. Oxford University Press.

Galanti, Geri-Ann 2000. An introduction to cultural differences. Western Journal of Medicine 172 (5), lk 335-336.

Gießler, Wolfram 2011. Von der monokulturellen zur transkulturellen Einrichtung: Diversity-Management im Gesundheitswesen. Van Keuk, Eva \& Ghaderi, Cinur \& Joksimovic, Lijljana \& David, Dagmar M. (toim). Diversity. Transkulturelle Kompetenz in klinischen und sozialen Arbeitsfeldern. Stuttgart: W. Kohlhammer Verlag, lk 104-116.

Gunaratnam, Yasmin 1997. Culture is not enough: a critique of multiculturalism in palliative care. Field, David \& Hockey, Jenny \& Small, Neil (toim). Death, Gender and Ethnicity. London: Routledge, lk 166-186.

Gunaratnam, Yasmin 2014. Morbid mixtures: Hybridity, pain and transnational dying. Subjectivity 7 (1), lk 74-91 (doi: 10.1057/sub.2013.21).

Gysels, Marjolein \& Evans, Natalie \& Meñaca, Arantza \& Andrew, Erin V. W. \& Bausewein, Claudia \& Gastmans, Chris \& Gómez-Batiste, Xavier \& Gunaratnam, Yasmin \& Husebø, Stein \& Toscani, Franco \& Higginson, Irene J. \& Harding, Richard \& Pool, Robert 2012. Culture Is a Priority for Research in End-of-Life Care in Europe: A Research Agenda. Journal of Pain and Symptom Management 44 (2), lk 285-294 (doi: 10.1016/j. jpainsymman.2011.09.013).

Han, Byung-Chul 2005. Hyperkulturalität. Kultur und Globalisierung. Berlin: Merve Verlag.

Helman, Cecil G. 2000. Culture, Health and Illness. London \& New York: Oxford University Press Inc.

Helman, Cecil 2006. Why medical anthropology matters. Anthropology Today 22 (1), lk 3-4 (doi:10.1111/j.1467-8322.2006.00409.x).

Henke, Antje \& Thuss-Patience, Peter \& Behzadi, Asita \& \& Henke, Oliver 2017. Endof-life care for immigrants in Germany. An epidemiological appraisal of Berlin. PLOS ONE (doi: 10.1371/journal.pone.0182033).

Henke, Oliver \& Behzadi, A \& Mauter, D., \& Henke, Altje. 2015. Utilization of Advanced Directives among Migrants in Berlin. Retrieved from https://www.pkv-stiftung.de/ projekte/forschung-und-wissenschaft.html.

Jansky, Maximiliane \& Nauck, Friedemann 2015. Palliativ- und Hospizversorgung von Menschen mit Migrationshintergrund. Aktueller Stand und Handlungsempfehlungen für Hospiz- und Palliativversorger. Universitätsmedizin Göttingen (http://www. palliativmedizin.med.uni-goettingen.de/de/media/Palliativ-_und_Hospizversorgung_ von_Menschen_mit_Migrationshintergrund.pdf - 19. november 2018).

Jansky, Maximiliane \& Owusu-Boakye, Sonja \& Nauck, Friedemann 2017a. More knowledge, more action. Palliative care for people with a migration background. EAPC Blog. European Association for Palliative Care (https://eapcnet.wordpress.com/2017/02/06/ 
more-knowledge-more-action-palliative-care-for-people-with-a-migration-background/19. november 2018).

Jansky, Maximiliane \& Owusu-Boakye, Sonja \& Nauck, Friedemann 2017b. Palliative care for patients with Turkish or Arabic migration background in Lower Saxony: A survey from palliative care professionals' perspective. Bundesgesundheitsblatt Gesundheitsforschung Gesundheitsschutz 60 (1), lk 45-54 (doi: 10.1007/s00103-016-2473-x).

Jovanovic, Maja M. 2012. Cultural competency and diversity among hospice palliative care volunteers. American Journal of Hospice and Palliative Medicine 29 (3), lk 165-170 (doi: 10.1177/1049909111410415).

Kai, J. \& Beavan, J. \& Faull, C. 2011. Challenges of mediated communication, disclosure and patient autonomy in cross-cultural cancer care. British Journal of Cancer 105 (7), lk 918-924 (doi: 10.1038/bjc.2011.318).

Koffman, Jonathan 2014. Servicing multi-cultural needs at the end of life. Journal of Renal Care 40 (S1), lk 6-15 (doi: 10.1111/jorc.12087).

Kumagai, Arno K. \& Lypson, Monica L. 2009. Beyond Cultural Competence: Critical Consciousness, Social Justice, and Multicultural Education. Academic Medicine 84 (6), lk 782-787 (doi:10.1097/ACM.0b013e3181a42398).

Milberg, Anna \& Torres, Sandra \& Ågård, Pernilla 2016. Health Care Professionals' Understandings of Cross-Cultural Interaction in End-of-Life Care: A Focus Group Study. PLOS ONE 11 (11), e0165452 (doi: 10.1371/journal.pone.0165452).

Munday, D. F. \& Johnson, S. A. \& Griffiths, F. E. (2003). Complexity theory and palliative care. Palliative Medicine 17 (4), lk 308-309 (doi: 10.1191/0269216303pm771oa).

Paal, Piret. 2012. Ist "Kultur" in Palliative Care von Belang? Überlegungen aus anthropologischer Sicht. Zeitschrift für Palliativmedizin 13, lk 24-27 (doi: 10.1055/s0031-1301108).

Paal, Piret 2018. Culturally sensitive palliative care research: what should we do with 'those people', or what should we do with ourselves? Kuehlmeyer, Katja \& Klingler, Corinna \& Huxtable, Richard (toim). Ethical, Legal and Social Aspects of Healthcare for Migrants: Perspectives from the UK and Germany. London \& New York: Routledge, lk 162-174.

Paal, Piret \& Bükki, Johannes 2017. "If I had stayed back home, I would not be alive any more..." - Exploring end-of-life preferences in patients with migration background. PLOS ONE 12 (4), e0175314 (doi: 10.1371/journal.pone.0175314).

Paal, Piret \& Grünewald, Gabriele \& Rizzi, Katharina 2018. Kultursensible Hospizund Palliativarbeit. Konzepte und Kompetenze. Umsorgen - Hospiz- und Palliativarbeit praktisch. Kohlhammer.

PALQUALSUM 2016 = Das Lebensende zwischen zwei Lebenswelten. Wissenschaftler der Freien Universität untersuchen, warum russischsprachige Zuwanderer nur selten Angebote der deutschen Palliativversorgung in Anspruch nehmen. "PALQUALSUM: Palliative Lebensqualität - Inanspruchnahme von Versorgungsangeboten durch russischsprachige Migrantinnen und Migranten”. Freie Universität Berlin (kodulehekülg http://www.fu-berlin.de/campusleben/forschen/2016/160310-palliativ-russischemigranten/index.html - 15. november 2018).

Pask, Sophie \& Pinto, Cathryn \& Bristowe, Katherine \& van Vliet, Liesbeth \& Nicholson, Caroline \& Evans, Catherine J \& George, Rob \& Bailey, Katharine \& Davies, 
Joanna M. \& Guo, Ping \& Daveson, Barbara A \& Higginson, Irene J \& Murtagh, Fliss E. M. 2018. A framework for complexity in palliative care: A qualitative study with patients, family carers and professionals. Palliative Medicine 32 (6), lk 1078-1090 (doi: 10.1177/0269216318757622).

Pollack, Harold \& Kronebusch, Karl 2009. Health Insurance and vulnerable populations. Economic Research Initiative on the Uninsured. University of Michigan (www.umich. edu/ eriu/pdf/wp5.pdf - 19. november 2018).

Razum, Oliver 2010. Gesundheit von Migranten: Hintergründe. Migration und Gesundheit. Kulturelle Vielfalt als Herausforderung für die medizinische Versorgung. Hamburg: Ethikrat (https://www.ethikrat.org/fileadmin/PDF-Dateien/Veranstaltungen/ jahrestagung-2010-razum.pdf - 20. november 2018).

Razum, Oliver \& Karrasch, Laura \& Spallek, Jacob 2016. [Migration: A neglected dimension of inequalities in health?] Bundesgesundheitsblatt Gesundheitsforschung Gesundheitsschutz 59, lk 259-265 (doi: 10.1007/s00103-015-2286-3).

Rommelspacher, Birgit 2005. Die Anerkennung der Ausgrenzung. Nicht der Multikulturalismus, sondern die Integrationspolitik ist gescheitert. iz3w 284, lk 22-26 (https:// www.iz3w.org/zeitschrift/ausgaben/284_multikulturalismus/inh - 20. november 2018).

Salis Gross, Corina S. A. E. \& Sariaslan, Emine \& Schneeberger Geisler Susanne 2014. Palliative care sensitive to the needs of the migrant population in Switzerland - final report on a study commissioned by the Swiss Federal Health Agency. Zürich.

Sarría-Santamera, Antonio \& Hijas-Gómez, Ana-Isabel \& Carmona, Rocío \& GimenoFeliú, Luís Andrés 2016. A systematic review of the use of health services by immigrants and native Populations. Public Health Reviews 37 (28) (doi: 10.1186/s40985-016-0042-3).

Schrank, Beate \& Rumpold, Tamara \& Amering, Michaela \& Masel, Eva Katharina \& Watzke, Herbert \& Schur, Sophie 2017. Pushing boundaries - culture-sensitive care in oncology and palliative care: a qualitative study. Psycho-Oncology 26 (6), lk 763-769 (doi:10.1002/pon.4217).

Soom-Amman, Eva \& Salis Gross, Corina 2014. Palliative Care und Migration. Literaturrecherche zum Stand der Forschung einer diversitätssensiblen Palliative Care. Bern: Bericht der Firma PHS Public Health Services.

Spiegel Online 2010 = Merkel erklärt Multikulti für gescheitert. Spiegel Online. Politik 16.10.1010 (http://www.spiegel.de/politik/deutschland/integration-merkel-erklaertmultikulti-fuer-gescheitert-a-723532.html - 15. november 2018).

Süddeutsche Zeitung 2018 = Ramadan, Dunja. Was ist deutsch? Süddeutsche Zeitung 01.01.2018 (https://www.sueddeutsche.de/politik/zugehoerigkeit-was-ist-deutsch1.3753795? reduced=true -15 . november 2018).

Trompenaars, Fons \& Hampden-Turner, Charles 2006. Riding the waves of culture: Understanding Cultural Diversity in Business (2. tr). Fairfield: McGroW Hill.

Tsing, Anna Lowenhaupt 2004. Friction. An Ethnography of Global Connection. Princeton: Princeton University Press.

Tylor, Edward B. 2005 [1871]. Die Anfänge der Cultur: Untersuchungen über die Entwicklung der Mythologie, Philosophie, Religion, Kunst und Sitte. Hildesheim: Olms. von Unger, Hella 2014. Partizipative Forschung. Einführung in die Forschungspraxis. Springer VS. 
Wasner, Maria \& Kurz, A. K. 2016. Schulungsbedarf von Hospizhelfern in interkultureller Kompetenz (Abstract). Zeitschrift für Palliativmedizin 17 (05), lk 1-59 (doi: 10.1055/s-0036-1594174).

Welsch, Wolfgang 1995. Transkulturalität. Zur veränderten Verfasstheit heutiger Kulturen. Zeitschrift für Kulturaustausch 45 (1), lk 39-44.

WHO 2014. Strengthening of Palliative Care as a Component of Integrated Treatment throughout the Life Course. Journal of Pain \& Palliative Care Pharmacotherapy 28 (2), lk 130-134 (doi: 10.3109/15360288.2014.911801).

WHO 2015. Improving Access to Palliative Care. Infographics on Palliative Care (http:// www.who.int/ncds/management/palliative-care/pc-infographics/en/-20. november 2018).

WHO 2016. Strategy and action plan for refugee and migrant health in the WHO European Region. Copenhagen: Regional Office for Europe 66th Session (http://www.euro. who.int/en/health-topics/health-determinants/migration-and-health/publications/2016/ strategy-and-action-plan-for-refugee-and-migrant-health-in-the-who-european-region 20. november 2018).

WHO 2018. Declaration of Astana. Global Conference on Primary Health Care. World Health Organization and the United Nations Children's Fund (UNICEF) (http://www. who.int/primary-health/conference-phc/declaration - 20. november 2018).

\title{
Summary
}

\section{Cultural competencies and the meaning of migration history in palliative care and hospice work: A hermeneutic discussion guided by patient narratives}

\author{
Piret Paal \\ Institute of Nursing Science and Practice, Paracelsus Medical Private University \\ Research Associate and Coordinator of the WHO Collaborating Centre in Salzburg, Austria \\ piret.paal@pmu.ac.at
}

Keywords: palliative care, hospice, culture, migration, patient narratives

This article discusses the need for cultural competencies in hospice and palliative care. The following discussion is based on patient narratives. The interviews (37) were conducted in Munich, Germany, in 2016. Half of the interviewees had a migration history. Thematic analysis revealed that (1) for most of the patients the aims of palliative and hospice care were ambiguous; (2) the end of life was connected with a loss of autonomy and wish for hastened death. Discussions about life, illness, and death were not perceived as burdensome, whereas discussing the end of life seemed challenging. A comparison between two groups revealed that for people with migration history the notion of 'dying at home' may cause additional suffering, and thus may need screening and additional attention from professionals. Cultural competence in the hospice and palliative care setting is providing safety by treating each patient as an individual and not as a member of some specific group. The task for medical anthropology in this context is to strive for research free from standpoint epistemology and stereotypes. 